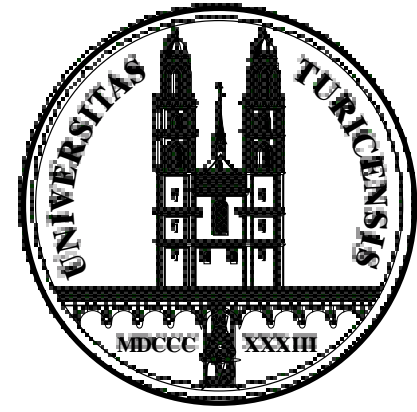

Institute for Empirical Research in Economics

University of Zurich

Working Paper Series

ISSN 1424-0459

Working Paper No. 29

Ecological Tax Reform with Exemptions for the Export Sector in a two Sector two Factor Model

Reto Schleiniger

December 1999 


\title{
Ecological Tax Reform with Exemptions for the Export Sector in a two Sector two Factor Model ${ }^{*}$
}

\author{
Reto Schleiniger \\ Institute for Empirical Research in Economics \\ Blümlisalpstrasse 10, 8006 Zurich Switzerland
}

\begin{abstract}
This present paper analyzes an energy tax reform that exempts the energy-intensive export sector from paying the energy tax and uses the additional revenue to cut existing taxes in all sectors. To that end, a two sector two factor model of an open economy that is small on the import side but not on the export side is applied. Within this model, an equivalence between a tax reform with and without exemption of the export sector is derived. The equivalence occurs because in both tax schemes the tax burden is shifted through an increasing producer price of labor from the domestic to the foreign household.
\end{abstract}

Keywords: Environmental tax reform, tax incidence, general equilibrium model JEL classification: $\quad$ D50, H22, Q40

\footnotetext{
* I am indebted to Stefan Felder for drawing my attention to the topic of this paper and for many valuable comments and to Martin Brown for further helpful suggestions.
} 


\section{Introduction}

In Europe environmentally motivated energy-taxes have already been introduced in five countries. In Denmark, Norway and Sweden, where environmental tax rates are substantial, energy- and export-intensive sectors are at least partly exempted from the tax ${ }^{1}$. In Finland and the Netherlands such tax reliefs on the use of carbon dioxide do not exist. However, the tax rates in these two countries are so moderate that the resulting commodity price increases are in the range of only a few percent ${ }^{2}$.

Germany also plans to enforce an energy tax with exemptions for industries that are both energy- and export intensive ${ }^{3}$. Switzerland, on the other hand, intends to exempt all big emittents from carbon dioxide taxes, provided they commit themselves to reducing their emissions to a negotiated level ${ }^{4}$.

From an efficiency point of view such tax exemptions have no rationale since marginal abatement cost across emittents will not be equalized and, therefore, total costs to attain a given standard are not minimized. The motivation behind such tax reliefs is political. If a country unilaterally introduces environmental taxes such as an energy tax, its export industry fears to lose international competitiveness and market share. Even if the tax receipts are redistributed, the energy-intensive export sector still opposes the tax reform because the sector will turn out to be a net tax payer ${ }^{5}$. Hence, given a strong political influence of this sector, it is excluded from paying the new energy tax.

The additional revenue of an environmental tax reform is typically used to reduce other existing taxes such as the tax on labor income. It is noteworthy that a general reduction of existing taxes does not exclude the energy-intensive export sector. Such a reimbursement is realized in Sweden and Norway and planed in Germany ${ }^{6}$. Denmark, on the other hand, distributes the revenue back to the tax paying sector. In the case of Sweden, Norway and Germany, therefore, the energy-intensive export sector not only is exempted from the energy

\footnotetext{
${ }^{1}$ For an overview on existing air pollutant taxes in Europe and Japan, see Cansier and Krumm (1997). For a more general overview on environmental taxes in OECD countries, see OECD (1995).

${ }^{2}$ Cansier and Krumm (1997), p.65.

${ }^{3}$ Böhringer and Rutherford (1997), p.192.

${ }^{4}$ Art. 9, Swiss federal bill on the reduction of $\mathrm{CO}_{2}$ emissions.

${ }^{5}$ The political economy of environmental politics goes back to the famous paper by Buchanan and Tullock (1975). For an overview on the political economy of environmental regulation, see Hahn (1990).

${ }^{6}$ Cansier and Krumm (1997), p.68.
} 
tax but at the same time profits from the reimbursement scheme. As a consequence, a net transfer to the energy-intensive export sector results.

Intuitively it can be expected that such a tax reform favors the exempted sector, which will expand at the cost of other sectors. Furthermore, since the exempted sector is energyintensive, the possibility arises that due to structural changes the tax reform can even lead to an increase in total energy use. However, this intuitive explanation does not consider endogenous factor price changes and implicitly assumes a reduction of labor taxes to lower the producer price of labor. It is the goal of this paper to take into account factor price adjustments by applying a general equilibrium model and to compare the results with a tax reform that does not discriminate between sectors. It is shown that, despite the labor tax cut, the producer price of labor increases in both scenarios and, as a consequence, the tax burden is shifted to the foreign household. As a result of this tax incidence both scenarios are equivalemt with respect to structural changes and total energy use.

The general equilibrium model used in the paper is a two sector two factor open economy model. This model type has often been applied since it was introduced by Harberger in 1962 . Interestingly though, it has not yet been used to analyze environmental tax reforms. While Bovenberg and de Mooij (1994a), in their well known paper on the double dividend, and Bovenberg and van der Ploeg (1994a) introduce only one factor, Bovenberg and de Mooij (1994b) as well as Bovenberg and van der Ploeg (1994b) use only one sector.

Besides that a large number of models exist that analyze environmental tax reform in a computable general equilibrium (see, for example, Ballard and Medema (1993), Goulder (1995a), Boyd, Krutilla and Viscusi (1995), Bovenberg and Goulder (1996) or Parry, Williams and Goulder (1999)). These models all incorporate many sectors and several factors, but they do not, with the exception of Böhringer and Rutherford (1997) ${ }^{7}$, address the topic of discriminating factor taxes within an environmental tax reform.

The structure of the paper is as follows: Section 2 introduces the model and derives its reduced forms for all prices and quantities. Section 3 discusses the results and explains why an equivalence of the exemption strategy with a general tax reform occurs. Section 4 extends the model and analyses the sensitivity of the results to model assumptions. Finally, section 5 concludes.

\footnotetext{
${ }^{7}$ In contrast to the model in the present paper, Böhringer and Rutherford (1997) do not allow for terms of trade to adjust.
} 


\section{The Model and its Reduced Forms}

The following model incorporates all features required to analyze a differentiated energy taxation of the export and domestic sector. Otherwise the model is kept as simple as possible.

Figure 1: The structure of the model

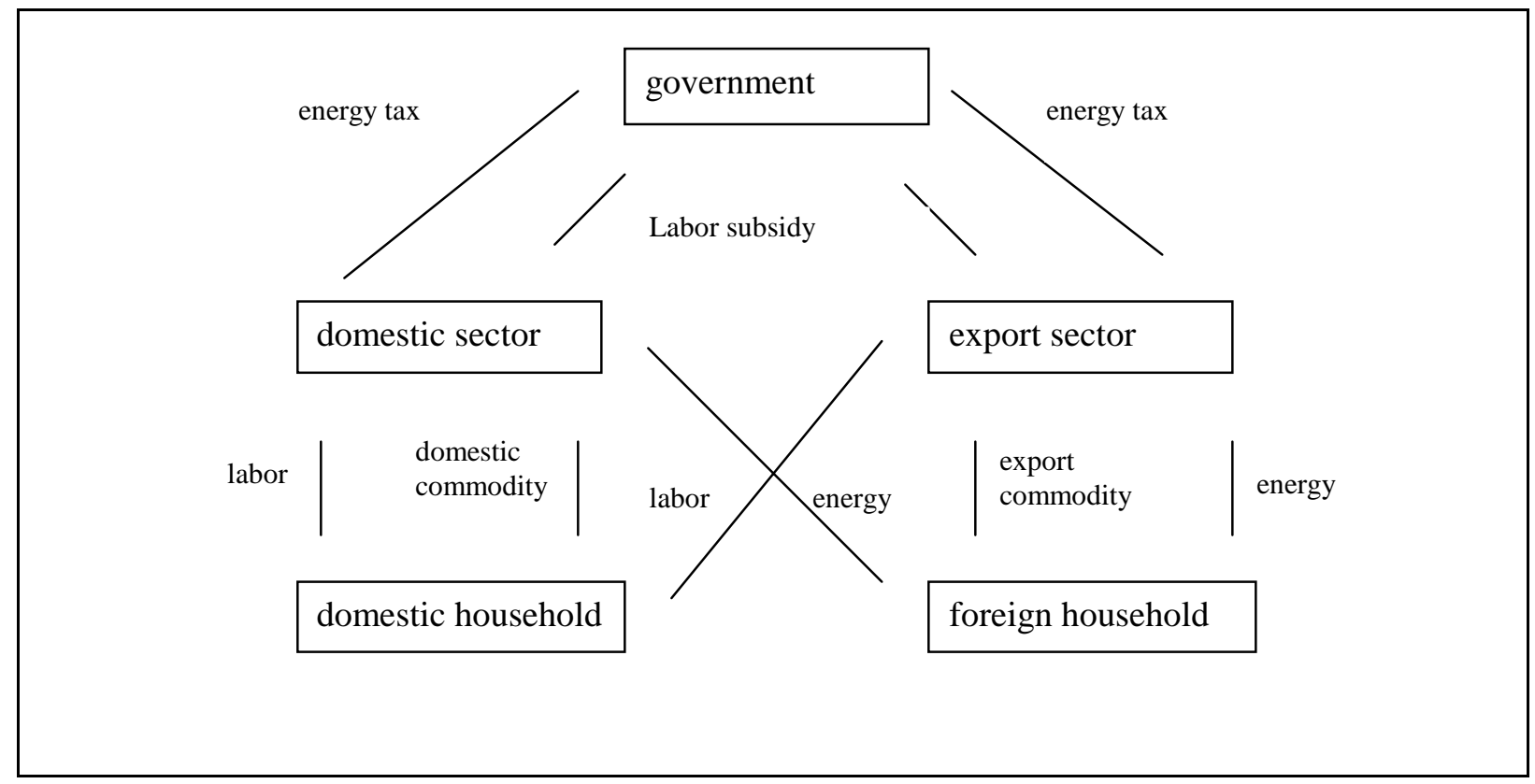

Figure 1 shows the structure of the model. There are two sectors producing exclusively for the domestic or the export market respectively. Each sector uses the two factors labor and energy. While labor is supplied by the domestic household alone, all energy is imported. Therefore, on the factor level, the domestic household trades energy (in the domestic good) with labor (in the exported good). Government transfers the energy tax yield back to labor. Table 1 gives a mathematical description of the model in levels.

Production:

Two representative firms in the sectors $d$ (domestic) and $f$ (foreign) produce at constant returns to scale (I.1). The implicit factor demand functions in (I.2) and (I.3) follow from profit maximization. The non-profit condition (I.4) is guaranteed by the assumption of perfect competition. The producer prices for the two factors labor and energy each include a quantity tax rate. While the tax rate on labor is equal across sectors (I.5), the tax on energy can vary (I.6). 
Table 1: The Model in Levels

\begin{tabular}{|lc}
\hline $\begin{array}{l}\text { Production: } \\
\text { Production-function } \\
\text { sector } \mathrm{i}=\mathrm{d}, \mathrm{f} \\
\text { First order condition }\end{array}$ & $Y_{i}=Y_{i}\left(L_{i}, E_{i}\right)$ \\
& $P_{Y i} \frac{\partial Y_{i}}{\partial L_{i}}=P_{l}^{p}$ \\
& $P_{Y i} \frac{\partial Y_{i}}{\partial E_{i}}=P_{e}^{p i}$ \\
Non profit condition & $P_{Y i} Y_{i}=P_{l}^{p} L_{i}+P_{e}^{p i} E$ \\
Producer prices & $P_{l}^{p}=P_{l}+t_{l}$ \\
Household: & $P_{e}^{p i}=\bar{P}_{e}+t_{e}^{i}$ \\
Utility function & $U=U\left(Y_{d}\right)$ \\
Budget constraint & $P_{Y d} Y_{d}=P_{l} \bar{L}$ \\
International trade: & \\
Exported good demand & $Y_{f}=Y_{f}\left(P_{Y f}\right)$ \\
Trade balance & $\bar{P}_{e} E=P_{Y f} Y_{f}$ \\
Government budget & $\sum_{i}^{i} E_{i}+t_{l} L=0$ \\
Labor market & $\sum_{i} L_{i}=\bar{L}$ \\
Total energy use & $\sum_{i} E_{i}=E$
\end{tabular}

Notation:

$Y_{i}$ : supply of commodity $\mathrm{i}$

$P_{l}: \quad$ after-tax wage rate

$L_{i}: \quad$ labor use in sector $\mathrm{i}$

$\bar{P}_{e}$ : $\quad$ world market price of energy

$E_{i}$ : energy use in sector i

$t_{l}$ : quantity tax rate on labor

$P_{Y i}:$ price of commodity $\mathrm{i}$

$t_{e}^{i}$ : quantity tax on energy in sector $\mathrm{i}$

$P_{l}^{p}$ : producer price of labor

$\bar{L}$ : total labor supply (exogenous)

$P_{e}^{p i}:$ producer price of energy in sector $\mathrm{i}$

$E$ : total energy supply 


\section{Household:}

The domestic household consumes the domestic product alone (I.7) while it supplies labor at a given quantity which gives rise to the budget constraint (I.8). With such a formulation of the model, the analysis of excess burden in the labor market is excluded. However, the present paper does not focus on labor market distortions but on structural adjustments between sectors and on total energy use.

International trade:

The demand of the exported commodity depends on the commodity price (I.9). This implies a rather specialized export commodity since its price is not given by the world market. Such an assumption is plausible for highly developed small countries that sell differentiated products such as cars or machinery ${ }^{8}$. On the other hand, energy is treated as a homogenous factor that is traded worldwide at a given price. With other words, the small country assumption holds on the import but not on the export side which allows terms of trade to vary. The trade balance (I.10) follows from Walras' law.

\section{Government:}

To keep the model simple all tax rates in the benchmark are set to zero. The government, therefore, does not supply any public good (I.11). Given the assumption of an exogenous labor supply such a formulation is equivalent to a benchmark with existing labor taxes financing a fixed amount of a public good. To start with no energy taxes, on the other hand, is a more severe restriction which is discussed below.

In the counterfactuals government only transfers energy tax income to labor. The tax reform therefore describes an introduction of taxes and subsidies rather than an increase and corresponding decrease of existing taxes.

In order to derive reduced forms for a marginal change in energy taxes the model is loglinearized. Table 2 presents the model in relative changes (denoted by a tilde except indicated otherwise) around an initial equilibrium. To further simplify the analysis quantities are normalized such that all prices are unity9.

\footnotetext{
${ }^{8}$ See, for example Dervis, De Melo and Robinson (1982), p. 225.

${ }^{9}$ With such a formulation, there is no difference between quantity and ad valorem tax rates. Also the shares as presented in table 2 can be expressed in quantities alone.
} 
Table 2: The Model in Relative Changes

\begin{tabular}{|c|c|}
\hline Output & $\tilde{Y}_{i}=\alpha_{l}^{i} \widetilde{L}_{i}+\alpha_{e}^{i} \widetilde{E}_{i}$ \\
\hline Factor-substitution & $\tilde{L}_{i}-\tilde{E}_{i}=\sigma_{i}\left(\tilde{P}_{e}^{p i}-\tilde{P}_{l}^{p}\right)$ \\
\hline Non-profit condition & $\tilde{P}_{Y i}=\alpha_{l}^{i} \tilde{P}_{l}^{p}+\alpha_{e}^{i} \tilde{P}_{e}^{p i}$ \\
\hline Producer prices & $\begin{array}{c}\tilde{P}_{l}^{p}=\tilde{P}_{l}+\tilde{t}_{l} \\
\tilde{P}_{e}^{p i}=\tilde{t}_{e}^{i}\end{array}$ \\
\hline Budget constraint & $\tilde{P}_{Y d}+\tilde{Y}_{d}=\tilde{P}_{l}$ \\
\hline Exported good demand & $\tilde{Y}_{f}=\varepsilon \tilde{P}_{Y f}$ \\
\hline Trade balance ${ }^{10}$ & $\tilde{E}=\tilde{P}_{Y f}+\tilde{Y}_{f}$ \\
\hline Government budget & $\tilde{t}_{l}=-\frac{\sum_{i} \tilde{t}_{e}^{i} E_{i}}{\bar{L}}$ \\
\hline Labor market & $\sum_{i} \gamma_{i} \tilde{L}_{i}=0$ \\
\hline Total energy use & $\sum \delta_{i} \widetilde{E}_{i}=\widetilde{E}$ \\
\hline
\end{tabular}

Parameters:

$\sigma_{i}:$ substitution elasticity in sector $\mathrm{i}$

$\varepsilon$ : $\quad$ price elasticity of foreign commodity demand

Shares:

$$
\begin{aligned}
& \alpha_{l}^{d} \equiv \frac{L_{d}}{Y_{d}}=\frac{L_{d}}{\bar{L}} \equiv \gamma_{d} \quad \text { (labor intensive) } \\
& \alpha_{l}^{f} \equiv \frac{L_{f}}{Y_{f}}=\frac{L_{f}}{E}=\frac{E_{d}}{E} \equiv \delta_{d} \\
& \alpha_{e}^{d} \equiv \frac{E_{d}}{Y_{d}}=\frac{E_{d}}{\bar{L}}=\frac{L_{f}}{\bar{L}} \equiv \gamma_{f} \\
& \alpha_{e}^{f} \equiv \frac{E_{f}}{Y_{f}}=\frac{E_{f}}{E} \equiv \delta_{f} \quad \text { (energy intensive) }
\end{aligned}
$$

Taxes:

$$
\begin{aligned}
& \tilde{t}_{e}^{i} \equiv \frac{d t_{e}^{i}}{\bar{P}_{e}}=d t_{e}^{i} \\
& \tilde{t}_{l} \equiv \frac{d t_{l}}{P_{l}}=d t_{l}
\end{aligned}
$$

Endogenous variables:

$\tilde{Y}_{i}, \tilde{L}_{i}, \tilde{E}_{i}, \widetilde{P}_{Y i}, \tilde{P}_{l}^{p}, \widetilde{P}_{e}^{p i}, \widetilde{P}_{l}, \tilde{t}_{l}, \tilde{E}$

Exogenous variables:

$\tilde{t}_{e}^{i}$

Now the reduced forms can be derived for the two policy scenarios. The first scenario does not discriminate between the two sectors such that $\tilde{t}_{e}{ }^{d}=\tilde{t}_{e}^{f} \equiv \tilde{t}_{e}$. The second scenario only taxes the domestic sector and uses the tax yield to subsidize labor in both sectors, i.e. $\tilde{t}_{e}^{d}>0$

\footnotetext{
${ }^{10}$ Note that this equation is redundant.
} 
and $\tilde{t}_{e}^{f}=0$. Table 3 presents the reduced forms for the two scenarios and, for simplicity, introduces a notation for the change of the producer price of labor $\left(\tilde{P}_{l}^{p} / \tilde{t}_{e} \equiv \Delta\right.$ and $\left.\tilde{P}_{l}^{p} / \tilde{t}_{e}{ }^{d} \equiv \Delta_{e x}\right)$. Because all the variables of the model are expressed in relative changes, the results in the two columns of table 3 are elasticities.

Table 3: The Effect of Energy Tax Changes on Prices and Quantities ${ }^{11}$

\begin{tabular}{|c|c|c|}
\hline & No exemption & Exemption \\
& $\tilde{t}_{e}$ & $\tilde{t}_{e}^{d}$ \\
\hline$\tilde{P}_{l}^{p}$ & $\frac{-\gamma_{d}\left(E_{f} / \bar{L}+\alpha_{e}^{d} \sigma_{d}\right)-\gamma_{f}\left(\alpha_{e}^{f} \varepsilon+\alpha_{e}^{f} \sigma_{f}\right)}{\gamma_{d}\left(\alpha_{e}^{d}-\alpha_{e}^{d} \sigma_{d}\right)+\gamma_{f}\left(\alpha_{l}^{f} \varepsilon-\alpha_{e}^{f} \sigma_{f}\right)} \equiv \Delta$ & $-\gamma_{d} \alpha_{e}^{d} \sigma_{d}$ \\
$\tilde{P}_{Y d}$ & $\alpha_{l}^{d} \Delta+\alpha_{e}^{d}$ & $\alpha_{l}^{d} \Delta_{e x}+\alpha_{e}^{d}$ \\
$\tilde{P}_{Y f}$ & $\alpha_{l} \Delta+\alpha_{e}$ & $\alpha_{l} \Delta_{e x}$ \\
$\tilde{Y}_{d}$ & $\alpha^{d} \Delta+E_{f} / \bar{L}$ & $\alpha_{e}^{d} \Delta_{e x}$ \\
$\tilde{Y}_{f}$ & $\varepsilon\left(\alpha_{l}^{f} \Delta+\alpha_{e}^{f}\right)$ & $\varepsilon \alpha_{l}^{f} \Delta_{e}$ \\
$\tilde{E}$ & $(1+\varepsilon)\left(\alpha_{l}^{f} \Delta+\alpha_{e}^{f}\right)$ & $(1+\varepsilon) \alpha_{l}^{f} \Delta_{e x}$ \\
\hline
\end{tabular}

\section{Discussion of Results}

\subsection{An Equivalence Result}

From the results of table 3 an equivalence of the two scenarios with respect to domestic and exported commodity demand and total energy use can be derived. Formally, this equivalence is evident from the fact that the elasticities of the three variables $\tilde{Y}_{d}, \tilde{Y}_{f}$ and $\tilde{E}$ in the two tax scenarios differ only by a constant factor. Equation (1) presents this factor, which depends on the cost shares and the substitution elasticities in production but not on the price elasticity of the demand for the exported good.

\footnotetext{
${ }^{11}$ See the appendix for the deriviation of the reduced forms
} 


$$
\frac{\tilde{Y}_{d} / \tilde{t}_{e}}{\tilde{Y}_{d} / \tilde{t}_{e}^{d}}=\frac{\tilde{Y}_{f} / \tilde{t}_{e}}{\tilde{Y}_{f} / \tilde{t}_{e}{ }^{d}}=\frac{\tilde{E} / \tilde{t}_{e}}{\tilde{E} / \tilde{t}_{e}^{d}}=\frac{\Delta+E_{f} / E_{d}}{\Delta_{e x}}=\frac{1}{\alpha_{l}^{f}}+\frac{\alpha_{e}^{f} \sigma_{f}}{\alpha_{l}^{f} \alpha_{l}^{d} \sigma_{d}}
$$

If we set the exogenous energy tax rates $\left(\tilde{t}_{e}\right)$ and $\left(\tilde{t}_{e}\right)$ such that their ratio equals the calculated factor in equation (1), the same relative changes $\tilde{Y}_{d}, \tilde{Y}$ and $\tilde{E}$ result with both tax reforms.

The explanation for this equivalence is that, with respect to the three variables $\tilde{Y}_{d}, \tilde{Y}$ and $\tilde{E}$, the two scenarios are again equivalent to a change of the producer price of labor $\widetilde{P}$. Looking first at the scenario with exemption, it can be seen from the budget constraint (II.6) in table 2 that domestic commodity demand $\tilde{Y}_{d}$ solely depends on the real after-tax wage rate (denoted $\tilde{P}_{l}^{r}$ in equation (2)).

$$
\widetilde{P}_{l}^{r} \equiv \widetilde{P}_{l}-\widetilde{P}_{Y d}=\widetilde{P}_{l}-\tilde{t}_{l}-\widetilde{P}_{Y d}=\left(\Delta_{e x}+\alpha_{e}^{d}-\alpha_{l}^{d} \Delta_{e x}-\alpha_{e}^{d}\right) \tilde{t}_{e}^{d}
$$

The r.h.s. of equation (2) explains why the energy tax rate has no direct effect on the real after-tax wage rate and, therefore, on domestic commodity demand. It shows that the price increase of the domestic commodity due to the energy tax $\left(-\alpha_{e}^{d}\right)$ is exactly offset by the raise of the nominal wage rate $\left(+\alpha_{e}^{d}\right)$. The domestic household pays the energy tax on the consumption side but the tax yield is fully redistributed to the household on the factor side. Note that in a model with no existing taxes, the imposition of a marginal tax does not create a tax-base effect. Therefore, the additional consumer expenses correspond to the additional tax yield which, in the present model, is redistributed to the household ${ }^{12}$. Hence, since the energy tax has no direct influence on domestic commodity demand but only an indirect effect through the producer price of labor, the scenario with tax exemption is equivalent to a corresponding change of the labor price. This equivalence is not restricted to domestic commodity demand but also includes demand for exported commodity and total energy use. The reduced forms in table 3 for $\tilde{Y}$ and $\tilde{E}$ show that they are only determined by the producer price of labor. While the demand for the export good depends on the nominal price of the good, which, in

\footnotetext{
${ }^{12}$ On the negative taxe-base effect, see Bovenberg and De Mooij (1994a), p.1088.
} 
turn, is a function of the labor price alone, total energy demand is restricted by supply and price of the export good alone (see (II.8) in table 2).

The equivalence between the tax exemption scenario and a change of the labor price holds for the three variables $\tilde{Y}_{d}, \tilde{Y}$ and $\tilde{E}$. However, it does not apply to the sector-specific variables $\widetilde{L}_{i}$ and $\tilde{E}_{i}$, since factor price ratios in the tax scheme with exemptions and with an altered labor price respectively are not equal.

The scenario without exemption, on the other hand, is fully equivalent to a labor price change. If we normalized prices such that the energy tax rate would be zero, the tax reform without exemption would consist of a labor price change only. Instead of changing the producer prices of both factors, the same real effects are achieved when changing the price of one factor at a corresponding rate.

Thus, with respect to $E, Y_{d}$ and $Y_{f}$ both tax scenarios can be represented by a change of the producer price alone. Therefore, the same real effects result if we set the energy taxes at corresponding rates.

\subsection{Structural Changes and Total Energy Use}

When discussing the impact of the energy tax reform, the three variables $E, Y_{d}$ and $Y_{f}$ are of major concern. The change of total energy use stands for the ecological effect of the tax reform and its so-called first dividend ${ }^{13}$. The second dividend, on the other hand, is represented by the change of domestic commodity demand, which, according to (I.7) in table 1, exclusively determines utility. Within the present model, a second dividend might occur since terms of trade vary and therefore, part of the energy tax burden can be shifted abroad. Since environmental quality is not an explicit argument in the utility function of the model, the two dividends cannot be integrated.

Finally, the size of the export sector has, in a comparative static model without transaction costs, no direct welfare implications but, nevertheless, is politically most relevant. As the political experience with green tax reforms clearly shows, the export sector opposes the reform when it expects to loose market share.

\footnotetext{
${ }^{13}$ The different dividend terms are discussed by Goulder (1995b).
} 
Because of the equivalence of the two tax scenarios exemption and no exemption with respect to $\tilde{E}, \tilde{Y}$, and $\tilde{Y}$, the impact on the variables can be analyzed with one scenario only. Since the formulas for the exemption case are more simple, this scenario is chosen.

First we look at the impact on the producer price of labor in the last column of table 3 . The different terms of the elasticity in table 3 represent the output and substitution effects of factor price changes on labor demand. To clarify this point, equation (3) restates the labor market equilibrium with the factor price changes $\tilde{P}$ and $\tilde{t}$ :

$$
\tilde{P}_{l}^{p}\left(\gamma_{d}\left(\alpha_{e}^{d}-\alpha_{e}^{d} \sigma_{d}\right)+\gamma\left(\alpha_{l} \varepsilon-\alpha_{e} \sigma\right)\right)+\tilde{t}_{e}^{d} \gamma_{d} \alpha_{e}^{d} \sigma_{d}=\tilde{L}=0
$$

As explained above, the energy tax increase has no direct output-effect on the domestic commodity and, as a consequence, on labor demand. Therefore the nominator of the elasticity in the second column of table 3 (the last term on the 1 .h. s. of equation (3)) only includes the substitution effect due to an energy tax increase. The denominator, on the other hand, lists all the effects on labor demand due to the producer price change of labor. Of the four terms in the denominator, only the first $\left(\gamma_{d} \alpha_{e}^{d}\right)$ is positive, describing a positive output-effect in the domestic sector when real income of the domestic household rises. The three remaining terms are all negative, representing a negative substitution effect in the domestic sector as well as negative output- and substitution effects in the export sector, respectively. If we plausibly assume the three negative effects to outweigh the positive effect, i.e. an increase in the producer price of labor decreases labor demand ${ }^{14}$, then the denominator is negative and the producer price of labor increases due to the energy tax reform.

A higher producer price of labor, in turn, increases the nominal wage rate as well as the price of both commodities. Since the price on the export commodity is paid by foreigners, the real wage of the domestic household and, as a consequence, domestic commodity demand increases. As a result, within the present model, an energy tax reform with or without exemption yields a second dividend, provided an increase in the producer price of labor decreases labor demand.

The resulting second dividend can also be explained with a terms of trade effect. In the scenario with exemption a higher labor price increases the price of the export good and, since the price of imported energy is fixed, improves the commodity terms of trade.

\footnotetext{
${ }^{14}$ In fact, this assumption is necessary for the stability of the equilibrium.
} 
Of course, the higher price of the export good lowers export demand. Therefore, even in the scenario that exempts the export industry from energy taxation, the industry loses international competitiveness due to the higher producer price of labor ${ }^{15}$.

The trade balance (II.8) in table 2 allows to derive easily the conditions for total energy use. Eliminating $\tilde{Y}$ in the trade balance using the demand for the exported commodity (II.7) yields:

$$
\widetilde{E}=(1+\varepsilon) \tilde{P}_{Y}
$$

And with $\widetilde{P}_{Y f}>0$ we have the following relationship between changes in energy use and the price elasticity of foreign demand:

$$
\operatorname{sign}[\tilde{E}]=\operatorname{sign}[1-|\varepsilon|]
$$

With an elastic demand of the export good the proceeds from selling the good abroad decrease and less energy can be imported, with an inelastic demand more energy can be bought.

Table 4 gives an overview of the impact of the tax reform on the three variables $\tilde{Y}, \tilde{Y}_{f}$ and $\widetilde{E}$.

Table 4: Overview on the Results

\begin{tabular}{|cccc|}
\hline & $\tilde{Y}$ & $\tilde{Y}_{f}$ & $\tilde{E}$ \\
$|\varepsilon|>1$ & $>0$ & $<0$ & $<0$ \\
$|\varepsilon|<1$ & $>0$ & $<0$ & $>0$ \\
\hline
\end{tabular}

Table 4 shows again that the domestic sector expands and the export sector declines independently on the size of the price elasticity $\varepsilon$. While the reform always yields a second dividend, the first dividend, i.e. a reduction of total energy use, only arises if demand for the exported good is elastic ${ }^{16}$. Since total energy use is restricted by the proceeds of the export

\footnotetext{
${ }^{15}$ At this point, the political economist might wonder, why the export industry still favors the exemption. While this question surely needs to be elaborated, it also should be stated that tax incidence is a complicated matter and is not always completely understood by policy makers.

${ }^{16}$ It also can be shown that with an increasing elasticity the first dividend gets larger at the cost of the second dividend.
} 
good, factor intensities in the two sectors have no influence on the import quantity. Therefore, the results as presented in table 4 apply to both cases with an energy-intensive export or an energy-intensive domestic sector.

\section{Extensions}

The model presented above is constructed to focus on the structural changes between the domestic and the export sector as well as to analyze total energy demand. To this end, we presented a simple model with fixed labor supply and two separated sectors. In this section we study the robustness of our results for more general assumptions.

If leisure is included in the household utility function total labor supply is no longer exogenous but a function of the real after-tax wage rate. With a positive wage elasticity of labor supply an outward shift of labor demand would not just increase the wage rate but also total labor input. However, with the rather small - uncompensated - wage elasticities of labor supply that are known from empirical studies ${ }^{17}$ the price effect would still be much larger than the quantity effect. Therefore, the results of the simple model would not be changed substantially.

The influence of labor supply on structural changes between the domestic and export sector as well as on total energy use seems to be more interesting if a Keynesian view is adapted and the nominal wage rate is fixed. With such an assumption, the adjustment in the short run can be analyzed. When the nominal wage rate is exogenous, the producer price of labor falls in both energy tax scenarios. As a consequence, in the scenario with exemption of the export sector, the commodity price also falls and leads to an expansion in production of that sector ${ }^{18}$. In the scenario without exemption, on the other hand, the export sector loses market share as the energy tax raises prices more than the labor subsidy lowers it. Note that this result, in contrast to the original model, now depends on the energy-intensity of the two sectors. Equation (6) presents the reduced form of exported commodity demand in the scenario without exemption when the nominal wage is fixed. It shows that with an energy-intensive export sector, i. e. $\alpha_{e}>\alpha_{e}^{d}$, export demand decreases and vice versa.

\footnotetext{
${ }^{17}$ Blundell (1992).

${ }^{18}$ Total energy use again depends on the size of the price elasticity of exported commodity demand. With an inelastic demand, total energy input declines, with an elastic demand the export proceeds increase and so does energy import.
} 


$$
\tilde{Y}_{f}=\varepsilon \tilde{P}_{Y f}=\varepsilon\left(\alpha_{l}^{f} \tilde{P}_{l}^{p}+\alpha_{e}^{f} \tilde{t}_{e}\right)=\varepsilon\left(-\alpha_{l}^{f} E / L^{f}+\alpha_{e}^{f} \tilde{t}_{e}\right)=\varepsilon\left(-\alpha_{e}^{d}+\alpha_{e}^{f}\right) \tilde{t}_{e}
$$

The aforementioned decrease is explained by the fact, that a tax reform without exemption leads to a transfer from the energy-intensive export to the labor-intensive domestic sector, as the energy-intensive sector is more heavily taxed while the labor-intensive sector receives relatively more subsidies.

From a political point of view the distinction between the short and the long run helps to explain why the export sector favors an exemption. As long as the nominal wage does not change such a solution would favor the export industry. But in the long run wage rates adjust and an equivalence between the two scenarios results.

Within a Keynesian fixed wage model, the structural change towards the export sector in the scenario with exemption is amplified if the exported good were an additional argument in the utility function and, therefore, substitution between the two commodities were possible. Since, in the scenario with exemption, the relative price of the exported commodity falls, not only foreign but also domestic demand would rise. The substitution effect would be larger the bigger the substitution elasticity and the higher the expenditure share of the exported commodity.

A further extension of the model refers to the tax system in the benchmark. If we allow for existing taxes on energy ${ }^{19}$ before the introduction of a tax reform, a tax-base effect must be taken into account. In the scenario with exemption, a decrease of the energy tax base, for example, would reduce the additional tax receipts such that the price increase due to the energy tax rise could not be compensated fully by redistributing the receipts to the household. In this case the scenario is not equivalent to an increase of the producer price of labor and, therefore, the equivalence with the scenario without exemption no longer holds. The quantitative impact of existing taxes on the results depends on the size of the existing tax as well as on the change of the tax base. In the present model, the tax base could also increase. This would be the case, if there is an existing tax on energy in both sectors and total energy use rises due to the tax reform (see equation (5)). It can be shown that a positive tax base

\footnotetext{
${ }^{19}$ As already mentioned, with labor supply fixed, existing taxes on labor are of little interest.
} 
effect can also occur if only energy input in the domestic sector is taxed in the benchmark. However, such a result is not very plausible ${ }^{20}$.

\section{Conclusion}

This paper has analyzed the effects of an environmental tax reform when the energy-intensive export sector is exempted from paying the energy tax while, at the same time, it still profits from the redistribution of the tax revenue. With a simple model, an equivalence with respect to the output in the two sectors and total energy use between a tax reform with and a reform without exemption has been derived. The explanation of this outcome is that, in the scenario without exemption, the energy tax has no direct effect on the consumption of the domestic commodity because the energy tax revenue is redistributed to the domestic household. With other words, the price increase due to the energy tax is fully compensated by an increase of the nominal after-tax wage rate such that the real wage rate is not affected. Hence, in the domestic sector, the discriminating energy tax only induces a factor substitution effect, which, ceteris paribus, increases labor demand. With fixed labor supply, this in turn increases the producer price of labor.

A higher producer price of labor, subsequently, raises the price of the exported commodity which leads to a reduction of output in the export sector. Although the scenario with exemption aims to exclude foreign consumers from the tax in an attempt to support the export sector, tax incidence across the wage rate shifts the tax burden fully abroad. The domestic household, on the other hand, profits from an increased real after-tax wage rate, since the discriminating energy tax is fully redistributed and part of the higher labor price is paid from abroad.

While the structural change induced by such a tax reform, i.e. an expansion of the domestic sector at the cost of the export sector, only depends on the plausible assumption that a higher labor price reduces labor demand, the effects on total energy use crucially depend on the price elasticity of export commodity demand. As the energy price is fixed and export is reduced, an elastic demand reduces export proceeds and consequently energy imports. An inelastic demand, on the other hand, increases revenues from abroad allowing more energy to be

\footnotetext{
${ }^{20}$ The condition for energy use in the domestic sector to rise is $\Delta_{e x}>\frac{\alpha_{l}^{d} \sigma_{d}}{\alpha_{e}^{d}+\alpha_{l}^{d} \sigma_{d}}$.
} 
imported. As a result, the first dividend of the green tax reform, i.e. the reduction of energy use, occurs in the present model only with elastic demand. Due to the equivalence between the tax schemes with and without exemption, this result also applies to a comprehensive environmental tax reform that does not exclude any sector.

The tax incidence from the domestic household to foreign consumers only applies in a model with flexible factor prices, which applies more to the long-run. However, in a Keynesian model with fixed nominal factor prices an incidence across the wage rate cannot occur and the two tax scenarios are not equivalent. While the energy-intensive export sector again loses market share in a scenario without exemption it expands when it is excluded from the energy tax.

The discussion of model extensions in the last section shows that the derived results apply to the long-run, to an economy where the export sector sells most of its production abroad and to a situation with no or only small existing energy taxes. 


\section{Appendix: Deriviation of Reduced Forms}

To derive the reduced form for the producer price of labor in the scenario with exemption we first eliminate commodity prices in the demand functions using the non-profit conditions (II.3) in table 2.

$$
\begin{aligned}
& \tilde{Y}_{d}=\tilde{P}_{l}-\tilde{P}_{Y d}=\tilde{P}_{l}^{p}-\tilde{t}_{l}-\left(\alpha_{l}^{d} \tilde{P}_{l}^{p}+\alpha_{e}^{d} \tilde{t}_{e}^{d}\right)=\tilde{P}_{l}^{p}-\alpha_{e}^{d} \tilde{t}_{e}^{d}-\left(\alpha_{l}^{d} \tilde{P}_{l}^{p}+\alpha_{e}^{d} \tilde{t}_{e}^{d}\right)=\alpha_{e}^{d} \tilde{P}_{l}^{p} \\
& \tilde{Y}_{f}=\varepsilon \tilde{P}_{Y f}=\varepsilon \alpha_{l}^{f} \tilde{P}_{l}^{p}
\end{aligned}
$$

Next, $\tilde{Y}_{d}$ and $\tilde{Y}_{f}$ in (A1) and(A2) are eliminated using the output equation (II.1).

$$
\begin{gathered}
\alpha_{l}^{d} \tilde{L}_{d}+\alpha_{e}^{d} \tilde{E}_{d}=\alpha_{e}^{d} \tilde{P}_{l}^{p} \\
\alpha_{l}^{f} \tilde{L}_{f}+\alpha_{e}^{f} \tilde{E}_{f}=\varepsilon \alpha_{l}^{f} \tilde{P}_{l}^{p}
\end{gathered}
$$

To eliminate energy demand in (A3) and (A4) equation (II.2) on factor-substitution is used.

$$
\begin{gathered}
\alpha_{l}^{d} \tilde{L}_{d}+\alpha_{e}^{d}\left(\tilde{L}_{d}-\sigma_{d}\left(\tilde{t}_{e}^{d}-\tilde{P}_{l}^{p}\right)\right)=\alpha_{e}^{d} \widetilde{P}_{l}^{p} \\
\alpha_{l}^{f} \tilde{L}_{f}+\alpha_{e}^{f}\left(\tilde{L}_{f}+\sigma_{f} \widetilde{P}_{l}^{p}\right)=\varepsilon \alpha_{l}^{f} \widetilde{P}_{l}^{p}
\end{gathered}
$$

Then labor demand can be stated as a function of the producer price of labor and the energy tax rate. In (A7) and (A8) the first term on the r. h. s. expresses the output effect the second term the factor-substitution effect on labor demand.

$$
\begin{aligned}
& \tilde{L}_{d}=\alpha_{e}^{d} \tilde{P}_{l}^{p}-\alpha_{e}^{d} \sigma_{d}\left(\tilde{P}_{l}^{p}-\tilde{t}_{e}^{d}\right) \\
& \tilde{L}_{f}=\alpha_{l}^{f} \varepsilon \tilde{P}_{l}^{p}-\alpha_{e}^{f} \sigma_{f} \tilde{P}_{l}^{p}
\end{aligned}
$$

Finally, we eliminate labor demand using the labor market equilibrium (II.10).

$$
\left[\gamma\left(\alpha_{e}-\alpha_{e} \sigma\right)+\gamma_{f}\left(\alpha_{l}^{f} \varepsilon-\alpha_{e}^{f} \sigma_{f}\right)\right] \tilde{P}_{l}^{p}+\gamma \alpha_{e} \sigma \tilde{t}_{e}=0
$$

Solving for $\tilde{P}_{l}^{p}$ we arrive at the result in table 3.

$$
\tilde{P}_{l}^{p}=\frac{-\gamma_{d} \alpha_{e}^{d} \sigma_{d}}{\gamma_{d}\left(\alpha_{e}^{d}-\alpha_{e}^{d} \sigma_{d}\right)+\gamma_{f}\left(\alpha_{l}^{f} \varepsilon-\alpha_{e}^{f} \sigma_{f}\right)} \tilde{t}_{e}^{d}
$$

Based on the result in (A10) the reduced forms of the remaining variables can easily be inferred. To derive the results for the tax reform without exemption in the first column of table 3 we follow the same lines. 


\section{References}

Ballard, Ch. and S. Medema (1993), The Marginal Efficiency Effects of Taxes and Subsidies in the Presence of Externalities: A Computable General Equilibrium Approach, Journal of Public Economics, 52, 199-213.

Blundell, R (1992), Labor Supply and Taxation: A Survey, Fiscal Studies 13 (3), 15-40.

Bovenberg, A.L. and De Mooij, R.A. (1994a), Environmental Levies and Distortionary Taxation, The American Economic Review 94 (4), 1085-1089.

Bovenberg, A.L. and De Mooij, R.A (1994b), Environmental taxes and Labor-Market Distortions, European Journal of Political Economy, 10, 655-683.

Bovenberg, L. A. and F. van der Ploeg (1994a), Environmental Policy, Public Finance and the Labor Market in a Second-Best World, Journal of Public Economics, 55, 349-390.

Bovenberg, L. A. and F. van der Ploeg (1994b), Green Policies and Public Finance in a Small Open Economy, Scandinavian Journal of Economics, 96(3), 343-363.

Bovenberg, L. A. and L. H. Goulder, 1996, Optimal Environmental Taxes in the Presence of Other Taxes: General-Equilibrium Analysis, American Economic Review, 86, 985-1000.

Böhringer, C. and T. F. Rutherford (1997), Carbon Taxes with Exemptions in an Open Economy: A General Equilibrium Analysis of the German Tax Initiative, Journal of Environmental Economics and Management, 32, 189-203.

Boyd, R., K. Krutilla and W.K. Viscusi (1995), Energy Taxation as a Policy Instrument to Reduce $\mathrm{CO}_{2}$ Emissions: A Net Benefit Analysis, Journal of Environmental Economics and Management, 29, 1-24.

Buchanan, J.M. and Tullock, G. (1975), Polluter's Profits and Political Response: Direct Control Versus Taxes, The American Economic Review 65 (1), 139-147.

Cansier, D. and Krumm, R. (1997), Air Pollutant Taxation: An Empirical Survey, Ecological Economics 23, 59-70.

Dervis, K. J. de Melo and S. Robinson (1982), General Equilibrium Models for Developement Policy, Cambridge University Press, Cambridge, England.

Goulder, L.H. (1995a), Effects of Carbon Taxes in an Economy with prior Tax Distortions: An Intertemporal General Equilibrium Analysis, Journal of Environmental Economics and Management 29(3), 271-297.

Goulder, L.H. (1995b), Environmental Taxation and the 'Double Dividend': A Reader's Guide, International Tax and Public Finance 2(2), 157-183.

Hahn, R.W. (1990), The political economy of Environmental Regulation: Towards a Unifying Framework, Public Choice 65(1), 21-47.

OECD (1995), Environmental Taxes in OECD Countries, Paris.

Parry, I. W. H., R. C. Williams and L. H. Goulder (1999), When Can Carbon Abatement Policies Increase Welfare? The Fundamental Role of Distorted Factor Markets, Journal of Environmental Economics and Management 37, 52-84. 